\title{
Enhancement of third-order nonlinearity of thermally evaporated GeSbSe waveguides through annealing
}

\author{
Michael Grayson, ${ }^{1}$ Mo Zohrabi, ${ }^{1}$ Kyuyoung BaE, ${ }^{1}$ Jiangang \\ Zhu, ${ }^{1}$ Juliet T. Gopinath, ${ }^{1,2,3}$ (D) And Wounjhang PARK ${ }^{1,3,{ }^{*}}$ \\ ${ }^{1}$ Department of Electrical, Computer \& Energy Engineering, University of Colorado, Boulder, CO 80309, \\ USA \\ ${ }^{2}$ Department of Physics, University of Colorado, Boulder, CO 80309, USA \\ ${ }^{3}$ Materials Science \& Engineering Program, University of Colorado, Boulder, CO 80309, USA \\ *won.park@colorado.edu
}

\begin{abstract}
Chalcogenides are a promising platform for infrared nonlinear optics but are susceptible to structural changes during fabrication that affect their linear and nonlinear optical properties. We analyze the structure and optical properties of thermally evaporated and annealed chalcogenide films. Thermally evaporated $\mathrm{Ge}_{28} \mathrm{Sb}_{12} \mathrm{Se}_{60}$ has an increased selenium content, bandgap, and concentration of heteropolar bonds. The concentration of heteropolar bonds can be reduced by annealing above the glass transition temperature, resulting in improved optical nonlinearity. We demonstrate a 4-fold enhancement of third-order nonlinearity in $\mathrm{Ge}_{28} \mathrm{Sb}_{12} \mathrm{Se}_{60}$ chalcogenide waveguides by thermal annealing and a decrease in propagation loss from 2.5 $\mathrm{dB} / \mathrm{cm}$ to $1 \mathrm{~dB} / \mathrm{cm}$ as an added benefit.
\end{abstract}

(C) 2019 Optical Society of America under the terms of the OSA Open Access Publishing Agreement

\section{Introduction}

The nonlinearity of optical materials allows for ultrafast modulation of light as well many light-matter interaction phenomena. A wide variety of nonlinear materials have been studied and used to produce novel devices in the visible and near infrared (NIR), but materials for the mid- (MIR) and far-infrared (FIR) have yet to be fully developed. Chalcogenide glasses are a promising candidate for NIR to FIR applications due to their broadband transmission and high nonlinear properties [1-3]. Preliminary demonstrations have shown that the nonlinearity in chalcogenide glasses can be used to create novel sources in the near to far-infrared [4-11]. Chalcogenide glasses have been implemented in spectroscopic measurements of molecular fingerprints $(6-20 \mu \mathrm{m})$ [12], room temperature blackbody radiation $(10 \mu \mathrm{m})$ [13,14], and MIR multispectral imaging $(2-7.5 \mu \mathrm{m})$ [15]. Though chalcogenides are a promising platform for nonlinear photonics, the changes their optical properties undergo during fabrication has yet to be fully characterized. Small changes in the composition or phase of a chalcogenide can result in a large change in its optical properties [16-18]. Most thin film deposition processes require the evaporation or dissociation of the chalcogenide source material into a vapor or liquid phase. This causes deviations in the optical properties of thin films from the bulk glass. We have found that thermal evaporation, a common physical vapor deposition (PVD) process, can increase the crystallinity of chalcogenides and induce a corresponding loss of nonlinearity. Rectifying this reduction of nonlinearity is central to the operation of nonlinear chalcogenide photonic devices and the success of chalcogenides as device platform in the MIR to FIR. To solve this problem, we propose a simple post-deposition annealing process that increases the optical nonlinearity by reducing the thin film's crystallinity. We assess the effectiveness of this process by analyzing the structure, optical properties, and composition of the thin films. We then choose the annealing 
condition which results in a film whose properties match most closely with that of the bulk chalcogenide.

A bulk chalcogenide glass is an amorphous matrix containing one or more chalcogen elements ( $\mathrm{Se}, \mathrm{S}, \mathrm{Te}$ ) [19]. Many elements can be added to the chalcogen to form a glass, but metalloids and post-transition metals are the most common elements. For each type of chalcogenide, a specific range of atomic concentrations are required to form a glassy state $[19,20]$. Amorphous chalcogenide glasses have excellent infrared transmission $(1-20 \mu \mathrm{m})$ [21], low glass transition temperatures $\left(150-350{ }^{\circ} \mathrm{C}\right)$ [16], and high indices of refraction $(2.2<n<2.8$ at $1.5-10.6 \mu \mathrm{m})$ [19]. Chalcogenides also have a large nonlinear index, $n_{2}$, a measure of the strength of third order interactions. In this work, $\mathrm{Ge}_{28} \mathrm{Sb}_{12} \mathrm{Se}_{60}$ was chosen for the large nonlinearity (383 times that of silica at $1.064 \mu \mathrm{m})$ [16], wide transmission window $(1-14 \mu \mathrm{m})$ [16], and low toxicity compared to As-containing compounds [16,22]. In addition, the low melting temperature enables easy deposition of thin films for fabrication of photonic devices. Commercial $\mathrm{Ge}_{28} \mathrm{Sb}_{12} \mathrm{Se}_{60}$, used as the bulk chalcogenide in this study, is formed through a melt quench method. Germanium, selenium, and antimony are melted in a silica ampoule at high temperatures $\left(800-900{ }^{\circ} \mathrm{C}\right.$ ) and mixed for 20-30 hours [16,20,23,24]. The ampoule is quenched in air or water to form a supercooled liquid or amorphous glass [16,20,23,24]. The ampoule is then annealed at the glass transition temperature to remove stress $[16,20,23,24]$. This produces a low stress and amorphous glass made up of a network of covalently bonded $\mathrm{Ge}, \mathrm{Sb}$, and $\mathrm{Se}$. While this process has been shown to produced bulk materials with high nonlinearity [16-18], it cannot be exactly replicated when depositing a thin film. The thin film deposition process necessarily induces changes in the film's composition, bond structure, and optical properties.

The primary methods for depositing a thin film of chalcogenide are sputtering, pulsed laser deposition, thermal evaporation, chemical vapor deposition, and spin-coating [25-28]. Thermal evaporation was chosen for our process due to its low cost, high film uniformity, and large range of deposition rates [27,29]. In thermal evaporation, sources of bulk chalcogenide are heated in high vacuum until they evaporate. The vapors travel upwards and condense on the substrate surface, resulting in a line-of-site deposition of the bulk material onto the substrate. Though thermal evaporation can produce uniform thin films, the amorphous nature and stoichiometry are affected. Differences in elemental vapor pressure, incongruent melting and vapor dissociation can cause changes in stoichiometry and a higher degree of crystallinity in the deposited film [27]. Thermal evaporation may also result in inclusions of trapped gas and thermal stress [29]. Both this study and previous studies show that the thermally evaporated films and the melt-quench prepared bulk glasses exhibit different optical nonlinearity $[1,16]$.

Z-scan measurements have demonstrated an $n_{2}$ of $11.3 \times 10^{-18} \mathrm{~m}^{2} / \mathrm{W}$ in melt-quench prepared bulk $\mathrm{Ge}_{28} \mathrm{Sb}_{12} \mathrm{Se}_{60}$ [16], while the $n_{2}$ of thermally evaporated $\mathrm{Ge}_{28} \mathrm{Sb}_{12} \mathrm{Se}_{60}$ waveguides has been measured to be $0.5 \times 10^{-18} \mathrm{~m}^{2} / \mathrm{W}[1,30]$. This decrease in nonlinearity shows that the deposition process has affected the nonlinear optical properties of the chalcogenide. Studies of other deposited chalcogenide films and thin film deposition processes also showed the nonlinear index varies widely from the bulk z-scan measurement $[3,31,32]$. This suggests the problem is not unique to $\mathrm{Ge}_{28} \mathrm{Sb}_{12} \mathrm{Se}_{60}$ and the thermal evaporation method. The cause of this decrease is the difference between the preparation methods of the bulk glass and the thin film. The bulk glass is formed by rapidly quenching a homogenous liquid into a solid, while the PVD film is formed by rapidly quenching a dissociated vapor into a solid. This difference results in changes in stoichiometry, linear index, and bond structure [25-27]. Nonlinearity is intimately related to the linear optical properties, the structure, and stoichiometry [16]. It is through systematic analysis of these properties that we determine the source of the change in optical nonlinearity and how to rectify it. The stoichiometry cannot be changed after evaporation, but the linear optical properties and bond structure can be modified through post-deposition annealing. 
Annealing is a controlled method of heating a metal or glass to induce some desired change [2,33-35]. These changes can be categorized into two groups: changes due to increased mobility and changes due to the equilibrium phase [34]. When a material is annealed the rates of diffusion increase for defects and solutes in the material [2]. This allows the material to relax into its equilibrium state at a faster rate [34]. This rate will increase as the temperature is increased. These increases in mobility lead to stress relaxation, crystal nucleation, crystal growth, and higher transformation rate into the equilibrium phase [33,36-39]. The second type of change that can occur with increasing temperature is a material phase change. This phase change can be from a liquid to a solid, or in some cases from one solid configuration to another [40]. Annealing of a glass such as chalcogenide below the melting point will result in crystallization and stress relaxation $[2,34,36,37]$. Annealing above the melting point will reform the chalcogenide melt with varying degrees of crystallinity depending on the maximum temperature and quench rate [40]. Our annealing study covers temperatures over this whole range and characterizes what changes have occurred by measuring the linear index, bandgap, and bond structure of the films. By performing this systematic analysis, we have determined that the decreases in the crystallinity of the films can be used to predict increases in nonlinearity.

Our study was performed by fabricating two types of samples: annealed thin films for spectroscopy and annealed waveguides for nonlinearity measurements. These samples are fabricated under the same conditions and compared to determine correlations between the optical nonlinearity and the changes in the thin film. Changes in nonlinearity are measured by generating a supercontinuum in the annealed waveguide. Changes in refractive index, bandgap, and bond structure are measured by using various spectroscopy techniques on the thin films. Through these measurements we find that the property most correlated with nonlinearity is the bond structure of the film. We find an inverse correlation between the crystallinity of the thin film and the nonlinear index. Through annealing the nonlinearity of the thermally evaporated chalcogenide is enhanced by four times. The roughness of the chalcogenide waveguide is also found to decrease with annealing, resulting in a lower propagation loss.

\section{Thin film fabrication and characterization}

Thin films of chalcogenide were fabricated to study the effects of annealing on thermally evaporated chalcogenide. Commercial $\mathrm{Ge}_{28} \mathrm{Sb}_{12} \mathrm{Se}_{60}$ (Schott Glass IRG 25) [22] was deposited at a rate of $1 \mathrm{~nm} / \mathrm{s}$ with a base pressure less than $10^{-6}$ torr using a molybdenum boat, an applied voltage of $20 \mathrm{~V}$ and a current of $72 \mathrm{~A}$. Chalcogenide films with a thickness of $330 \mathrm{~nm}$ on silicon substrates with $3 \mu \mathrm{m}$ of thermally grown $\mathrm{SiO}_{2}$ were used for ellipsometry, Raman, and Energy dispersive X-ray spectroscopy (EDS). Thin films of $1.2 \mu \mathrm{m}$ thickness on NBK7 microscope slides were used for visible/infrared spectrophotometry measurements. For annealing, samples were placed in a quartz tube furnace which was purged with $150 \mathrm{sccm}$ of nitrogen for 30 minutes. This flow rate was sustained for the entire process until the samples reached room temperature. The temperature of the furnace was raised at $10{ }^{\circ} \mathrm{C} / \mathrm{min}$ and then held at the annealing temperature for 1 hour. The samples were then cooled by turning off the furnace. The quenching rate depended on the initial temperature of the sample but was approximately $40{ }^{\circ} \mathrm{C} / \mathrm{min}$.

The first step is to verify that the thermally evaporated films are indeed $\mathrm{Ge}_{28} \mathrm{Sb}_{12} \mathrm{Se}_{60}$. The nonlinear refractive index in Ge-Sb-Se chalcogenides can vary by an order of magnitude over changes in $\mathrm{Sb}$ and Ge concentrations as small as 7\% [16,18,24,41,42]. EDS was performed in a JEOL JSM-7401F FE-SEM at $15 \mathrm{kV}$ with $10 \mu \mathrm{A}$ emission current. The atomic concentrations of 3 thin films were measured at 6 locations and averaged. Atomic concentrations in bulk samples were also determined for comparison. Figure 1(a) shows the measured composition, the bulk composition, and a 95\% confidence interval for each element. We have determined the thermally evaporated thin films have an increased selenium content by $5 \%$ with a stoichiometry of $\mathrm{Ge}_{25} \mathrm{Sb}_{10} \mathrm{Se}_{65}$. Changes in concentration between the bulk evaporation source and the deposited 
film can come from differences in the vapor pressure of the individual elements, from the formation of an incongruent melt during evaporation, or from the formation of molecular species in the evaporation vapor [27]. Selenium has a much higher vapor pressure than either Ge or $\mathrm{Sb}$; which cause a higher deposition rate and increased concentration in the deposited film [27]. An incongruent melt occurs when a chalcogenide melts to produce both a liquid and a solid phase. In $\mathrm{Ge}_{28} \mathrm{Sb}_{12} \mathrm{Se}_{60}$ the compound $\mathrm{Sb}_{2} \mathrm{Se}_{3}$ is known to melt first followed by $\mathrm{GeSe}_{2}$ [33]. This can cause an increased rate of evaporation for $\mathrm{Sb}_{2} \mathrm{Se}_{3}$ and an increased concentration of Se and Sb [29]. Finally during evaporation the atomic vapors can bind together to from molecular vapors which force the film to acquire a composition that matches a mixture of the molecular species [27]. $\mathrm{Ge}_{25} \mathrm{Sb}_{10} \mathrm{Se}_{65}$ corresponds exactly to mix of $\mathrm{GeSe}_{2}$ and $\mathrm{Sb}_{2} \mathrm{Se}_{3}$ molecular crystallites, $\left(\mathrm{GeSe}_{2}\right)_{83.3}\left(\mathrm{Sb}_{2} \mathrm{Se}_{3}\right)_{16.7}$ while $\mathrm{Ge}_{28} \mathrm{Sb}_{12} \mathrm{Se}_{60}$ cannot be expressed as a ratio of these two compounds. This suggests the dissociation of molecular $\mathrm{GeSe}_{2}$ and $\mathrm{Sb}_{2} \mathrm{Se}_{3}$ during evaporation is the primary source of stoichiometry difference. This new stoichiometry is still within the glass forming region and therefore will form a glass upon deposition [17,20]. The primary changes that should occur due to this change in composition are an increased bandgap of $1.75 \mathrm{eV}$ [23], a lower refractive index 2.5 [23,25,43], and a better glass forming ability [17]. It is not however expected to significantly impact the nonlinear index. Previous z-scan measurements of glasses with similar stoichiometry showed a slightly lower nonlinear index of $8-10 \times 10^{-18}$ $\mathrm{m}^{2} / \mathrm{W}[16,18,24,41,42]$, compared to $11.3 \times 10^{-18} \mathrm{~m}^{2} / \mathrm{W}$ [16], of the bulk $\mathrm{Ge}_{28} \mathrm{Sb}_{12} \mathrm{Se}_{60}$, but still much larger than the previously measured thin film nonlinear index of $0.5 \times 10^{-18} \mathrm{~m}^{2} / \mathrm{W}[1]$.
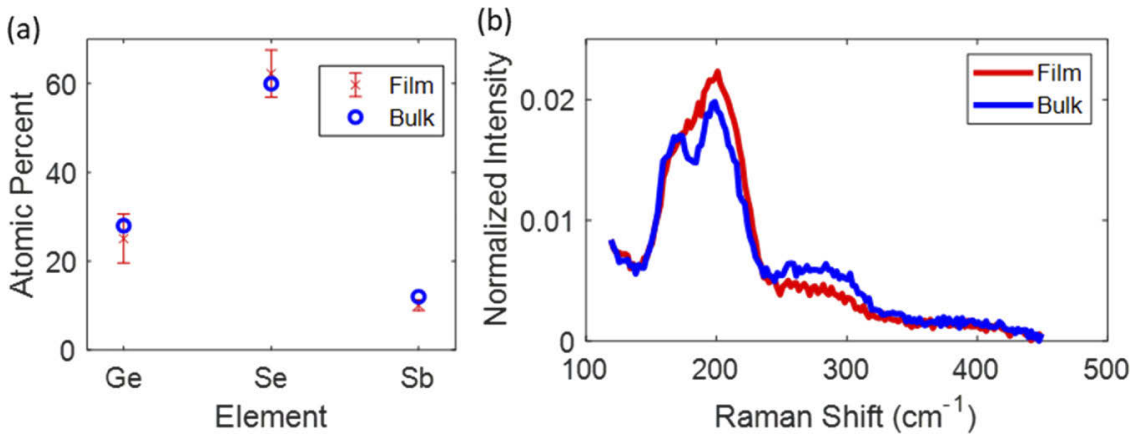

Fig. 1. (a) The measured atomic percentage for bulk and thermally evaporated thin film chalcogenide. The bulk composition is $\mathrm{Ge}_{28} \mathrm{Sb}_{12} \mathrm{Se}_{60}$ while the thin film concentration is $\mathrm{Ge}_{25} \mathrm{Sb}_{10} \mathrm{Se}_{65}$. Error bars are a 95\% confidence interval for the film. (b) The Raman spectra from bulk $\mathrm{Ge}_{28} \mathrm{Sb}_{12} \mathrm{Se}_{60}$ and a $330 \mathrm{~nm}$ thermally evaporated thin film. The spectra are normalized to unit area over the region $120-450 \mathrm{~cm}^{-1}$ by dividing their integrated area in this region. Three primary peaks occur each spectrum: The peak at $170 \mathrm{~cm}^{-1}$ corresponds to homopolar bonds, the peak at $200 \mathrm{~cm}^{-1}$ corresponds to heteropolar crystalline bonds, and the peak at $200 \mathrm{~cm}^{-1}$ corresponds to network bonds.

If the change in nonlinear index is not due to the stoichiometry of the film, then it is likely due to a change in the structure of the film $[16,23,44]$. Thermal evaporation does not conserve the amorphous glass phase of the bulk source. The source material vapors dissociate and crystalize mid-flight into $\mathrm{GeSe}_{2}$ and $\mathrm{Sb}_{2} \mathrm{Se}_{3}$ resulting in a higher degree of crystalline bonds in the film [27]. The substrate is also highly thermally conductive and will quickly quench any deposited chalcogenide. The deposited film does not have time to form a liquid during deposition and therefore primarily consists of $\mathrm{GeSe}_{2}$ and $\mathrm{Sb}_{2} \mathrm{Se}_{3}$ crystallites instead of an amorphous network [27]. Raman spectroscopy was used to characterize these initial changes in the bond structure of the evaporated thin films. Measurements were performed in a Renishaw InVia Raman microscope using a $25 \mathrm{~mW}, 514.5 \mathrm{~nm}$ Argon ion laser source. At high laser intensities, photodarkening 
can occur and modify the Raman spectrum [2,17]. To prevent changes in the spectrum due to optical annealing and photodarkening, excitation power was limited to $1 \%(<0.25 \mathrm{~mW})$ and the signal was collected for 1 minute from $100-2000 \mathrm{~cm}^{-1}$. Raman peaks were observed in the region between 100 and $400 \mathrm{~cm}^{-1}$, as shown in Fig. 1(b). For comparison, the spectra are normalized by the total integrated intensity after baseline subtraction. The differences in the three peaks at $170 \mathrm{~cm}^{-1}, 200 \mathrm{~cm}^{-1}$, and $280 \mathrm{~cm}^{-1}$ indicate that different concentrations of bonds exist in the thin film and in the bulk. The three visible peaks in these spectra each contain multiple overlapping peaks. The peak at $170 \mathrm{~cm}^{-1}$ (ranging from $160-180 \mathrm{~cm}^{-1}$ ), which has a larger area in the bulk sample than in the film, is due to the resonance of homopolar Ge-Ge $\left(170 \mathrm{~cm}^{-1}\right)$ and $\mathrm{Sb}-\mathrm{Sb}\left(160 \mathrm{~cm}^{-1}\right)$ bonds [17,23]. The peak at $200 \mathrm{~cm}^{-1}$ (ranging from 180-240 $\left.\mathrm{cm}^{-1}\right)$ is larger in the thin film sample and corresponds to heteropolar Sb-Se bonds $\left(190 \mathrm{~cm}^{-1}\right)$ and Ge-Se bonds $\left(200 \mathrm{~cm}^{-1}, 215 \mathrm{~cm}^{-1}\right)$ [17,23]. The third peak at $280 \mathrm{~cm}^{-1}$ ranging from (240-330 $\left.\mathrm{cm}^{-1}\right)$, which is smaller in the thin film sample, corresponds to network bonds such as Se rings $\left(240-250 \mathrm{~cm}^{-1}\right)$, Se chains $\left(235 \mathrm{~cm}^{-1}, 265 \mathrm{~cm}^{-1}\right)$, and Ge modifications to Se networks $\left(235-330 \mathrm{~cm}^{-1}\right)[17,23]$. To summarize, the thin film has a deficit in homopolar bonds $(160-180$ $\mathrm{cm}^{-1}$ ), and excess of heteropolar bonds $\left(180-240 \mathrm{~cm}^{-1}\right)$, and a deficit in network bonds (240-330 $\mathrm{cm}^{-1}$ ), compared to the bulk sample. The homopolar and network bonds are characteristic of an amorphous phase, while the heteropolar bonds are characteristic of a crystalline phase $[2,44]$. Therefore, the Raman spectrum shows that the thin film has a higher degree of crystallinity, which is expected in a thermally evaporated film due to vapor dissociation and crystallization [27]. It has been previously shown that changes in bond concentrations can lead to changes in nonlinear index [16-18,24,42]. We hypothesize that this change in bond concentration causes the decrease in optical nonlinearity in the thin film compared to bulk. Through annealing, the bond concentrations can be changed, and some amount of nonlinearity can be regained in the thin films.

To characterize how the film structure and phase will change under various annealing temperatures differential scanning calorimetry (DSC) and thermo-gravimetric analysis (TGA) were performed on $10 \mathrm{mg}$ of the bulk sample. Figure 2(a) shows the traces for both the DSC (in blue) and TGA (in red). DSC traces show a melting point as a peak and a crystallization point as a valley at the temperature at which the change occurs. TGA measures the weight of the material while it is heated to determine how the material evaporates with temperature. The DSC traces shows two peaks: a small peak at $300^{\circ} \mathrm{C}$ with an onset starting at $284^{\circ} \mathrm{C}$ which correspond to the glass transition temperature and a large peak at over $400^{\circ} \mathrm{C}$ which corresponds to the melting of initially $\mathrm{Sb}_{2} \mathrm{Se}_{3}$ and then $\mathrm{GeSe}_{2}$ [17,33,37-39]. The TGA shows the material begins to evaporate at above $500{ }^{\circ} \mathrm{C}$. This prevents the use of the melt-quench method on the thermally evaporated thin films to regain the bulk state. The film begins to evaporate at atmospheric pressure before it fully melts. Based on these results, the annealing temperatures were chosen to extend from below the glass transition temperature $\left(270^{\circ} \mathrm{C}\right)$ to the crystallization regime $\left(360^{\circ} \mathrm{C}\right)$. Annealing below the glass transition temperature $\left(0-285^{\circ} \mathrm{C}\right)$ is expected to reduce stress while annealing above the glass transition temperature and before crystallization $\left(285-360^{\circ} \mathrm{C}\right)$ will allow the film to relax to its equilibrium state. Annealing in the crystallization regime $\left(360-500^{\circ} \mathrm{C}\right)$ will cause the film to nucleate and grow crystallites. Figure 2(c) shows the Raman spectra of annealed thin films. As the samples are annealed at increasing temperatures the homopolar peaks $\left(160-180 \mathrm{~cm}^{-1}\right)$ and network peaks $\left(240-330 \mathrm{~cm}^{-1}\right)$ are observed to grow. Once the crystallization temperature is reached, they begin to shrink again, and the heteropolar peaks $\left(180-240 \mathrm{~cm}^{-1}\right)$ dominate. The bandgap of the thin films was also quantified after annealing by fitting the transmittance spectra of $1.2 \mu \mathrm{m}$ thick annealed thin films on $1 \mathrm{~mm}$ glass substrates. The data was fit with the Tauc method [45] using an exponent of 2 indicating an indirect bandgap. Figure 2(b) shows the changes in bandgap with annealing temperature. The band gap is initially low in the deposited film, becomes large at low annealing temperatures, and decreases with increasing annealing temperature. As 
the film crystallizes, a very sharp decrease in bandgap occurs [33]. The bandgap values in the region between 270 and $360{ }^{\circ} \mathrm{C}$ matches well with the previously reported bandgaps of bulk chalcogenides with similar compositions (1.7-1.75 eV) [16,23]. This implies that this annealing temperature range produces samples with a similar phase to the bulk chalcogenide.
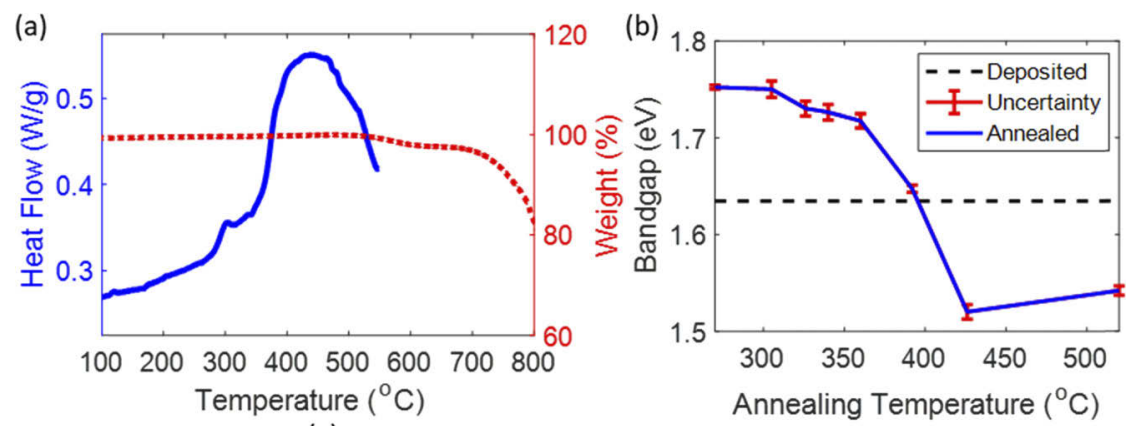

(c)

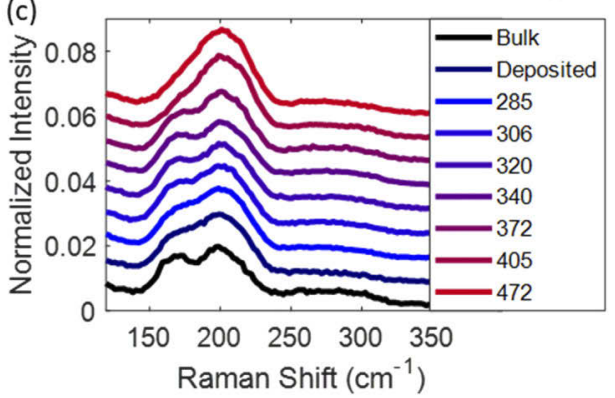

Fig. 2. (a) Differential scanning calorimetry (DSC) in red and thermo-gravimetric analysis (TGA) in blue of $10 \mathrm{mg}$ bulk $\mathrm{Ge}_{28} \mathrm{Sb}_{12} \mathrm{Se}_{60}$ at a scan speed of $10 \mathrm{~K} / \mathrm{min}$. The peak at 285 ${ }^{\circ} \mathrm{C}$ corresponds to the glass transition temperature while the peak at $360{ }^{\circ} \mathrm{C}$ corresponds to $\mathrm{Sb}_{2} \mathrm{Se}_{3}$ and $\mathrm{GeSe}_{2}$ crystallization. The sample begins to evaporate at $500{ }^{\circ} \mathrm{C}$. (b) The band gap of annealed $1.2 \mu \mathrm{m}$ thermally evaporated thin films in blue with the as deposited film in black. Error bars correspond to the $95 \%$ confidence interval for the Tauc plot regression. (c) The average area normalized Raman spectra of the thermally evaporated GeSbSe with increasing temperatures. The baselines of the spectra are offset from each other by .005 for visibility.

We have quantified the structural properties of the annealed samples by comparing their Raman spectra to the bulk sample. This was done by first calculating the difference spectra between the annealed sample and bulk, and then integrating the difference spectra to find the mean. The mean difference from bulk is shown in Fig. 3(a). Initially, the difference gradually decreases with increasing temperature as the sample's viscosity during annealing is reduced, resulting in a greater degree of relaxation to the amorphous state. Above $360^{\circ} \mathrm{C}$ the film begins to crystallize, and the Raman spectra become significantly different. The homopolar $\left(170 \mathrm{~cm}^{-1}\right)$ and networked $\left(280 \mathrm{~cm}^{-1}\right)$ bond areas are reduced significantly and the crystalline peak $\left(200 \mathrm{~cm}^{-1}\right)$ dominates. This can be seen qualitatively in Fig. 2(c) and quantitatively in Fig. 3(c). Our ultimate goal is to relate these changes due to annealing to the changes in nonlinear index. To make the nonlinearity measurements in the waveguides consistent with each other and avoid errors due to variations in fabrication, it is best to use the same waveguides in the optical measurements. For this reason, we also investigated successive annealing of the same thin film sample at various temperatures starting from the lowest temperature. This progressive annealing process leads to a slightly different temperature dependence of the Raman spectra. Figure 3(b) shows the mean difference for the progressive annealing process used on the waveguides. Overall, we observe the same 
behavior as that from the individually annealed samples shown in Fig. 3(a). The temperature of minimum mean difference occurs at a slightly lower temperature presumably because the changes in the film are building up at each annealing step. The Raman measurements on the progressively annealed samples were only performed up to the annealing temperature of $360{ }^{\circ} \mathrm{C}$ due to the onset of crystallization reducing the quality of the waveguides which can be observed in the increased linear loss and decrease nonlinearity. The chalcogenide also begins to evaporate above $400{ }^{\circ} \mathrm{C}$ which will change the stoichiometry of the film.

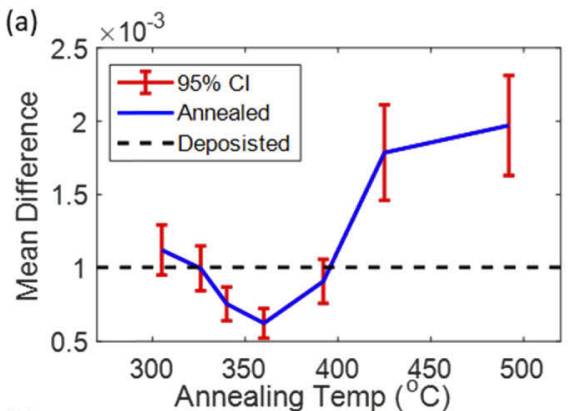

(c)
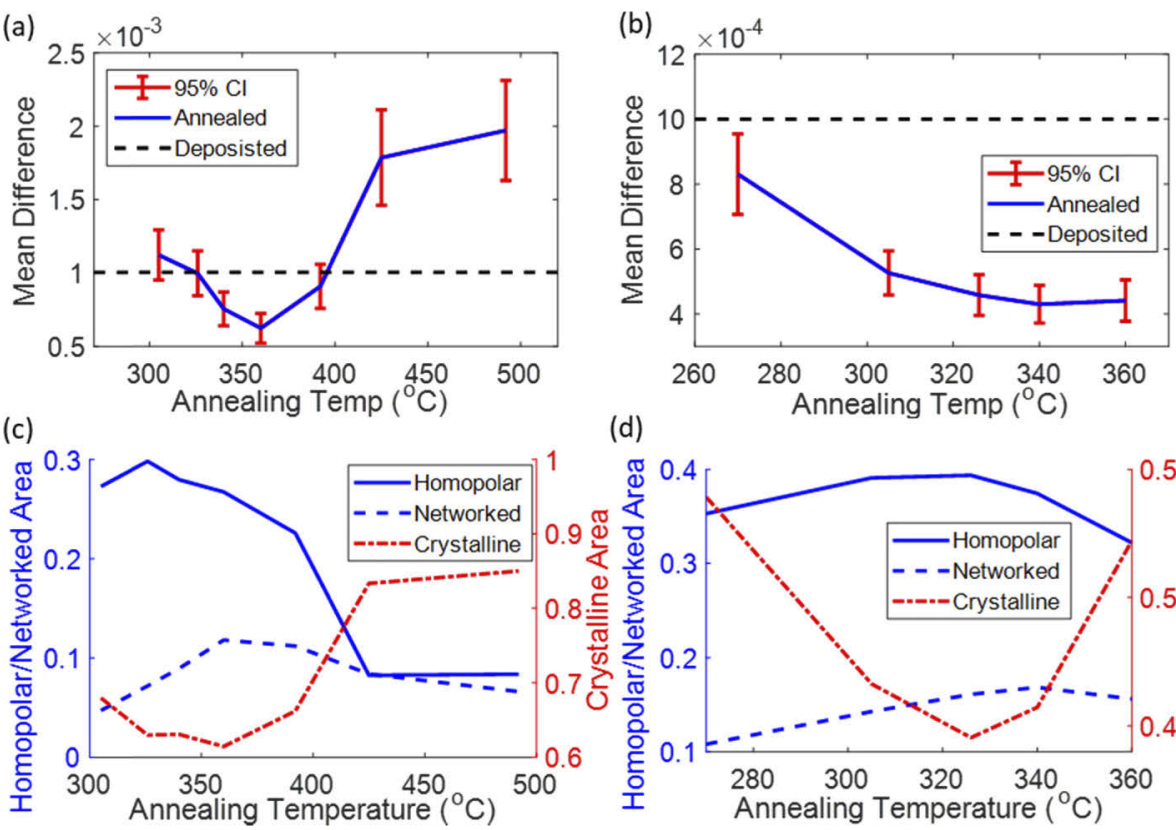

(d)

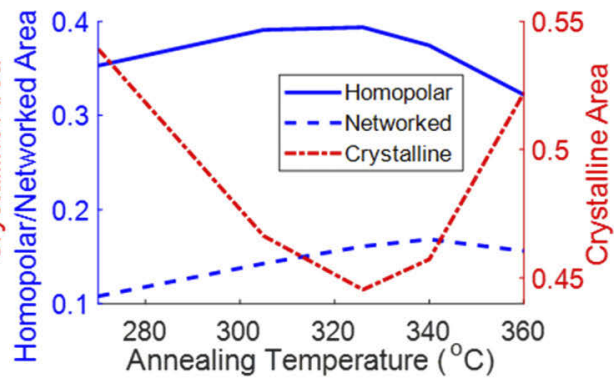

Fig. 3. (a) The mean difference between the annealed Raman spectra and bulk Raman spectra integrated over $120-400 \mathrm{~cm}^{-1}$. The error bars are the standard deviation in mean difference. Samples for this plot were annealed a single time for $1 \mathrm{hr}$. The black dotted line represents the unannealed sample. (b) The mean difference for the single sample annealed at multiple temperatures in a row. (c) The bond percentages of each type of bond calculated by integrating the spectra over their respective resonance regions for individual samples annealed for $1 \mathrm{hr}$. (d) The same bond concentration calculation for the single progressively annealed sample.

The Raman spectra can be further quantified by extracting the bond concentrations for each bond type. To extract relative changes in bond concentration the spectra are fit with 3 gaussians at each peak location. The change in the percentage of the spectral area corresponds to relative changes in bond concentrations for that bond type [23]. Figure 3(c) and Fig. 3(d) show the relative bond concentrations in the annealed thin films calculated by their normalized peak area. The point at which minimum crystallinity occurs coincides with maximum network and homopolar bonding. This point also coincides with the minimum mean difference between the annealed spectra and bulk. It has been suggested that homopolar $\mathrm{Ge}-\mathrm{Ge}, \mathrm{Sb}-\mathrm{Sb}$, and $\mathrm{Se}-\mathrm{Se}$ bonding is one of the causes of high nonlinearities in chalcogenides [16,46,47]. This corroborates the hypothesis that the thin film sample is locally crystallized causing a reduction in the number of homopolar bonds and consequently optical nonlinearity. Once again, the only difference between standard annealing and progressive annealing is that the progressive annealing exhibits the lowest crystalline point at a slightly lower temperature. This allows us to use the same waveguide 
for optical measurements by successively annealing it at progressively higher temperatures, as discussed below.

\section{Waveguide fabrication and characterization}

To verify that reducing the crystallinity of the films through annealing will enhance the nonlinearity, we have measured the supercontinuum generation spectra in annealed strip waveguides. In a waveguide that produces supercontinua from a known seed pulse, the amount of spectral broadening at a given input power can be compared to numerical solutions of the nonlinear Schrödinger equation (NLSE) to extract the nonlinearity of the material. This required the design, fabrication and linear characterization of GeSbSe waveguides. Two types of waveguides were designed to produce broad supercontinuum in either the annealed or unannealed case to demonstrate the changes in nonlinearity and material dispersion.

The process to fabricate waveguide devices consists of electron-beam lithography to produce the waveguide pattern, thermal evaporation to deposit the chalcogenide material, and lift-off to impart the lithography pattern on the film. Waveguides were fabricated on a $3 \mu \mathrm{m} \mathrm{SiO}_{2}$ thermal oxide grown on silicon wafer. The thermal oxide provides a low index cladding while the silicon substrate allows the waveguide facets to be cleaved along the silicon crystal axis. Substrates were coated with a bilayer of polymethyl methacrylate (PMMA) resist and exposed with $1500 \mu \mathrm{C}$ and $30 \mathrm{nA}$ beam. $330 \mathrm{~nm}$ of $\mathrm{Ge}_{28} \mathrm{Sb}_{12} \mathrm{Se}_{60}$ was then thermally evaporated under the same conditions as the $330 \mathrm{~nm}$ thin films used for material characterization. Waveguides were designed using a 2D finite difference vectorial mode solver for dispersion calculations and measured refractive index NLSE simulations for verification of supercontinuum production. The simulations include both the measured refractive index and waveguide geometry at each annealing temperature. The $330 \mathrm{~nm}$ waveguides were designed to have maximum broadening with the deposited film while an additional set of waveguides with a height of $380 \mathrm{~nm}$ were fabricated to have optimal dispersion at intermediate annealing temperatures. Both waveguides were $750 \mathrm{~nm}$ in width. Optically smooth facets were formed on either end of the waveguides by scoring and cleaving the silicon substrate. The resulting waveguide lengths were $5.35 \mathrm{~mm}$ for the $330 \mathrm{~nm}$ by $750 \mathrm{~nm}$ waveguides and $6.03 \mathrm{~mm}$ for the $380 \mathrm{~nm}$ by $750 \mathrm{~nm}$ waveguides. Light was coupled into and out of the waveguide using two lensed SMC fibers with a $1 \mu \mathrm{m}$ spot size each mounted to a 3-axis stage. Linear measurements were performed with a sub-MHz linewidth tunable Yenista TUNICS laser at $1 \mathrm{~mW}$ output power. Nonlinear measurements were performed with an Er-doped fiber laser with a maximum output power of $3 \mathrm{~mW}$, a repetition rate of $17.4 \mathrm{MHz}$, a central wavelength of $1550 \mathrm{~nm}$, and Fourier transform-limited pulse duration of 156 fs $[48,49]$. The pulse width of the laser was characterized through interferometric autocorrelation after propagating through a single-mode fiber whose length was equal to the fiber length used to couple the pulse into the chip.

For each annealing temperature the waveguide's linear loss, nonlinear loss, and spectral broadening were characterized. The linear loss was measured by coupling $1 \mathrm{~mW}$ of $1550 \mathrm{~nm}$ CW light into the TE mode of the waveguide. A Xenics Xeva infrared camera was then used to image the light scattered along the length of the waveguide. The scattered light intensity was fit with an exponential curve to determine the total linear propagation loss of the waveguide. Figure 4(a) shows the decrease in linear loss with increased annealing temperature. This decrease is due to a reduction in scattering loss from the gradual reflow of the waveguide at increasing temperatures. Scanning Electron Microscope (SEM) cross sections of the initial waveguide and the reflowed waveguide are shown in Fig. 4(b). The glass transition temperature defined by the viscosity occurs at approximately $285^{\circ} \mathrm{C}\left(10^{12}\right.$ Poise $)$ while the Littleton point, the point at which a glass deforms under its own weight, occurs at approximately $340{ }^{\circ} \mathrm{C}\left(10^{7.6}\right.$ Poise $)[39,50]$. The waveguide geometry remains intact at temperatures below $285^{\circ} \mathrm{C}$ and deforms completely as the temperature approaches $340^{\circ} \mathrm{C}$. We would expect then that the loss would decrease above 


\section{OpticS EXPRESS}

$285{ }^{\circ} \mathrm{C}$ and reach a minimum at $340{ }^{\circ} \mathrm{C}$, which is precisely what we observe in Fig. 4(a). We also observe a significant decrease in loss when the film is annealed at $270{ }^{\circ} \mathrm{C}$. Annealing below the glass transition temperature is used to reduce defects and stress. This decrease in loss at $270{ }^{\circ} \mathrm{C}$ is likely due to reduction in stress and defects that are induced during evaporation [2]. The increased scattering loss after $360{ }^{\circ} \mathrm{C}$ is due to crystallization of the sample which can be observed in the Raman spectra.

(a)

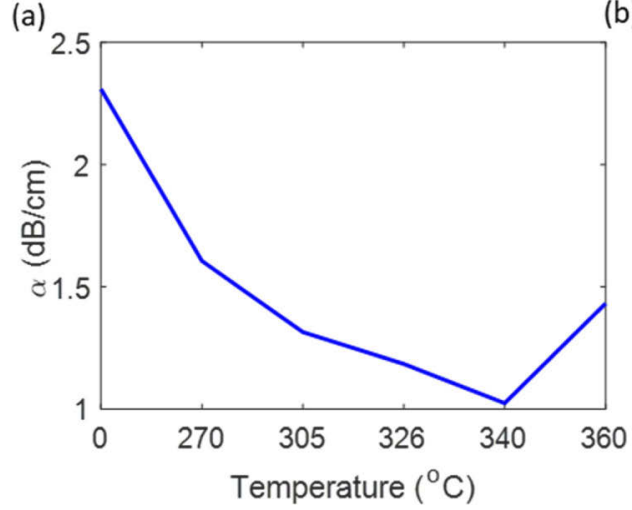

(b)

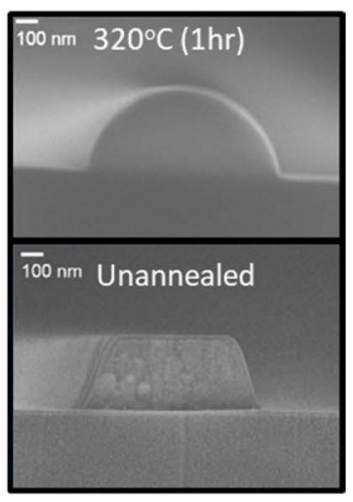

Fig. 4. (a) The propagation loss of $380 \mathrm{~nm}$ waveguide progressively annealed at each increasing temperature. The reduction is due the waveguide reflowing under decreased viscosity. The absorption loss at $1500 \mathrm{~nm}$ for this material is $0.2 \mathrm{~dB} / \mathrm{cm}$ [22]. (b) The cross-sectional image of a reflowed and un-reflowed $330 \mathrm{~nm}$ by $750 \mathrm{~nm}$ waveguide showing the changes in geometry.

Chalcogenides exhibit a third order nonlinearity and a nonlinear two photon absorption (TPA) $[18,30]$. TPA occurs for photons with energy above the half bandgap. The half bandgap for these films is between $1417 \mathrm{~nm}$ to $1653 \mathrm{~nm}$ depending on the annealing condition and significantly affects the pump pulse at $1550 \mathrm{~nm}$. Nonlinear loss was measured by coupling the 156-fs laser pulses into the waveguides and measuring the output power over a range of input powers. The input and output coupling efficiencies were determined by measuring the nonlinear transmission in both directions and equating the two-photon absorption coefficient [51]. The total coupling loss is calculated at low powers $(<0.2 \mathrm{~W}$ peak power) by assuming that linear loss dominates over TPA. The ratio of input coupling can then be determined by comparing the change in transmission loss at high power ( $>120 \mathrm{~W}$ peak power). The input coupling coefficient was determined to be $12 \pm 1 \%$ for both the $330 \mathrm{~nm}$ and $380 \mathrm{~nm}$ waveguides, while the output coupling efficiency was $4 \pm 1 \%$ for the $330 \mathrm{~nm}$ waveguide and $0.5 \pm 0.2 \%$ for the $380 \mathrm{~nm}$ waveguide. The nonlinear absorption in the waveguide is given by [Eq. (1)];

$$
-\frac{d I}{d z}=\alpha I+\beta z
$$

where $I$ is the intensity in the waveguide, $z$ is the propagation distance, $\alpha$ is the linear absorption, and $\beta$ is the TPA or nonlinear absorption. This differential equation can be solved analytically by integrating over the length of the waveguide $L_{w g}$ to obtain [Eq. (2)];

$$
\frac{1}{T}=\frac{\left(\exp \left(\alpha L_{w g}\right)-1\right) \beta}{\alpha} I_{i n}+\exp \left(\alpha L_{w g}\right)
$$

where $T$ is the ratio of the input and output power. This relationship is fit with linear regression to extract the TPA. The average TPA for the $330 \mathrm{~nm}$ and $380 \mathrm{~nm}$ waveguides was observed to be $0.024 \pm 0.009 \mathrm{~cm} / \mathrm{GW}$ and $0.020 \pm 0.01 \mathrm{~cm} / \mathrm{GW}$ respectively. These values are larger than the 


\section{Optics EXPRESS}

previously reported value of $0.014 \mathrm{~cm} / \mathrm{GW}$ at $1550 \mathrm{~nm}[1,30]$, due to the fact that most of the supercontinuum bandwidth occurs above the half bandgap. The TPA coefficient for chalcogenides increases significantly when the photon energy exceeds the half bandgap [18], and we observe the majority of the supercontinuum bandwidth to occur above the half bandgap. The TPA value we measure contains contributions from these higher frequencies due to the large bandwidth.

The nonlinear index was determined by measuring the spectral broadening as a function of power. The output of the waveguide was measured by an optical spectrum analyzer with a spectral range of 600-1700 nm. For each waveguide the average input power was varied from $0.01 \mathrm{~mW}$ to $3 \mathrm{~mW}$. Figure 5(a) shows the spectra of the seed pulse, a waveguide with a group velocity dispersion of $0.12 \mathrm{ps}^{2} / \mathrm{m}$, and a waveguide with a group velocity dispersion of $-0.82 \mathrm{ps}^{2} / \mathrm{m}$. Dispersion values are all calculated by taking the second derivative of propagation constants determined by mode simulations of the waveguide. The unannealed $330 \mathrm{~nm}$ waveguide and all the $380 \mathrm{~nm}$ waveguides achieved their maximum bandwidth below $3 \mathrm{~mW}$ with the lowest threshold for maximum bandwidth occurring at $326^{\circ} \mathrm{C}$.

(a)

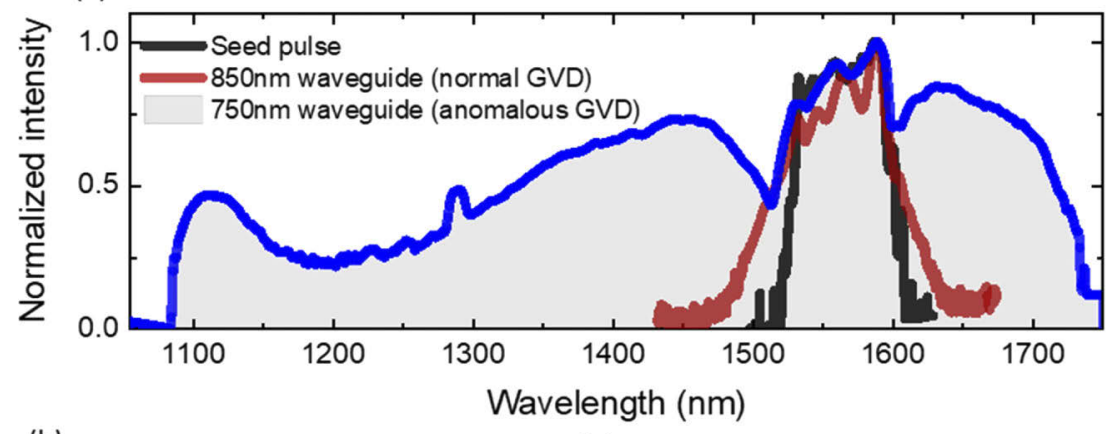

(b)

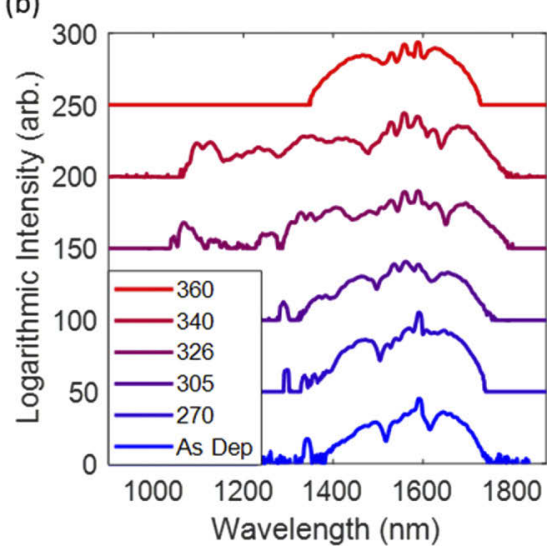

(c)

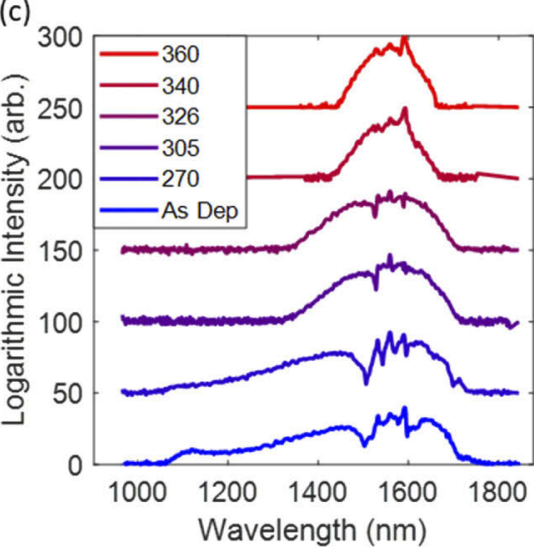

Fig. 5. (a) A comparison of the seed pulse spectrum, the output of a normal dispersion $\left(0.12 \mathrm{ps}^{2} / \mathrm{m}\right)$ waveguide $(330 \mathrm{~nm}$ high $\times 850 \mathrm{~nm}$ wide), and the output of an anomalous dispersion $\left(-0.82 \mathrm{ps}^{2} / \mathrm{m}\right)$ waveguide $(330 \mathrm{~nm}$ high $\times 750 \mathrm{~nm}$ wide). Both waveguides are unannealed. (b) The maximum broadening achieved from the $380 \mathrm{~nm}$ waveguides (3 $\mathrm{mW}$ of average pump power). The intermediate temperatures have the largest broadening due to both nonlinearity enhancement and dispersion design for operation at intermediate annealing temperatures. (c) The maximum broadening achieved from the $330 \mathrm{~nm}(2 \mathrm{~mW}$ of average pump power). Broadening decreases with temperature due dispersion changes. This waveguide was designed only for the as deposited dispersion. 
The $330 \mathrm{~nm}$ waveguides were dispersion-engineered to operate unannealed while the $380 \mathrm{~nm}$ waveguides were designed to operate at the expected optimal annealing temperature by using the measured index of refraction at each annealing temperature. This is the primary reason why the broadening decreases for the $330 \mathrm{~nm}$ waveguide while it increases for the $380 \mathrm{~nm}$ waveguide. The $326{ }^{\circ} \mathrm{C}$ spectrum was also the broadest spectrum measured, spanning from $1 \mu \mathrm{m}$ to beyond $1.7 \mu \mathrm{m}$, which is the cutoff of the spectrometer response. The split-step simulations predict the spectrum convers 1-3 $\mu \mathrm{m}$ or 3 octaves. Figure 6 shows the spectral broadening of the $380 \mathrm{~nm}$ waveguide annealed at $326^{\circ} \mathrm{C}$ as a function of input power along with a simulated spectrum. Simulations were performed by implementing the split-step Fourier method for solving the NLSE with the input 156 fs pulse. The NLSE simulation includes nonlinear index, nonlinear absorption, and dispersion up to the sixth order. This is the dispersion order at which significant changes in the simulation spectrum no longer occur for these waveguides [52]. The simulation does not include Raman scattering as it is not is not a significant effect at these pulse lengths. For pulses below 200 fs, short waveguides, and anomalous dispersion, higher order dispersion will dominate the broadening dynamics [53], which the split-step simulation corroborates. The experiment does show a small amount of Raman self-induced frequency shift in the pump region, but not enough to significantly affect the spectrum. The annealing process was observed to significantly impact dispersion of the waveguides which impacts the bandwidth of the supercontinuum. To accurately calculate the broadening for each waveguide the material dispersion was measured using ellipsometry for a $1 \mu \mathrm{m}$ film annealed under the same conditions as the waveguide. The waveguide cross-section geometry was also observed to change during annealing. As the waveguide's viscosity is reduced at higher annealing temperatures it slowly changes shape between the cross-sections shown in Fig. 4(b). The cross-sectional waveguide geometry was measured using SEM at each annealing step and used as the waveguide geometry for dispersion simulations. The dispersion was observed to change significantly with annealing resulting in large changes in supercontinuum bandwidth. The $330 \mathrm{~nm}$ waveguide was optimized to have significant broadening using the bulk dispersion while the $380 \mathrm{~nm}$ waveguide was engineered to have significant broadening at the intermediate annealing temperatures using the measured dispersion. A dispersive wave occurs at approximately $1.1 \mu \mathrm{m}$, demonstrating good agreement in the dispersion of the experiment and simulation. At low powers $(0.01-0.6 \mathrm{~mW})$ the broadening is dominated by self-phase modulation (SPM) of the soliton in the waveguide. Once the power is sufficient $(>0.6 \mathrm{~mW})$ that the solution fission length is less than the length of the waveguide, the broadening rate decreases and a dispersive wave or Cherenkov radiation is emitted from the ejected solitons [53].

The nonlinear index was fitted qualitatively by comparing the simulation and experiment to obtain a range of nonlinear index to perform a quantitative fit. The only free variable for these simulations is the nonlinear index; all other values (dispersion, linear loss, TPA, input power, pulse width, mode area, etc.) have been experimentally determined. Broadening was found to increase monotonically with nonlinear index and therefore any solution we find is a global solution. The range for fitting was: 0.01 to $10 \times 10^{-18} \mathrm{~W} / \mathrm{m}^{2}$. The fit was performed for each power (26 input powers) and each annealing condition ( 6 temperatures) assuming constant nonlinear index for each annealing condition. The changes in sensitivity of the spectrometer, output coupling, and dispersion make it difficult to directly compare any two spectra quantitatively through a difference or convolution method. To surmount these obstacles, we performed a fitting technique that compares the bandwidth or total area of the experimental and simulated spectra as a function of input power. The nonlinear index of refraction determines how the broadening increases with increasing power [53]. We can thus determine the nonlinear index by comparing the power dependent bandwidths of the simulations with that of the experiments. We first estimate the bandwidth by the area under the broadened spectrum. In experiments, the spectrum is truncated by the detection limit of the OSA. This truncation is accounted for by a constant 


\section{Optics EXPRESS}
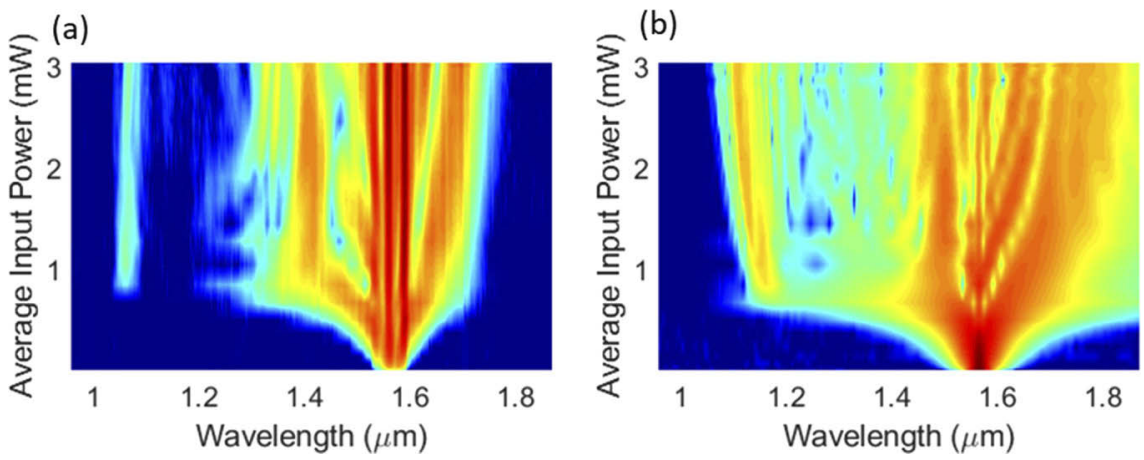

Fig. 6. (a) The spectral broadening of a $156 \mathrm{fs}$ pulse at $17.4 \mathrm{MHz}$ after propagating $6.03 \mathrm{~mm}$ in a GeSbSe $380 \mathrm{~nm}$ by $750 \mathrm{~nm}$ waveguide annealed at $326^{\circ} \mathrm{C}$ as a function of average input power before coupling into the chip. The spectrometer sensitivity is limited above $1700 \mathrm{~nm}$. (b) The split-step simulation using the measured material index and simulated geometric dispersion of the waveguide with a nonlinear index of $2.2 \times 10^{-18} \mathrm{~W} / \mathrm{m}^{2}$. A dispersive wave occurs at approximately $1.1 \mu \mathrm{m}$ for both simulation and experiment demonstrating good agreement.

scale factor. Next, we can fit the experimental data of bandwidth vs power with simulated results calculated for a range of nonlinear refractive index values. Finally, we determine the nonlinear index value by minimizing the fitting errors using the linear regression method.

Figure 7 (a) shows the calculated nonlinear index as a function of annealing temperature. The uncertainty in nonlinear index is $0.25 \times 10^{-18} \mathrm{~W} / \mathrm{m}^{2}$ and is primarily due to the uncertainty in the input coupling efficiency and dispersion of the annealed waveguides. The nonlinear index was also observed to depend on the degree of spectral broadening achieved, though less so than the TPA value. This is expected as the changes in nonlinear index are far smaller than that of the TPA value as the photon energy approaches the bandgap [18]. Usually the nonlinear index is inversely proportional to bandgap [16,18]. This is initially true for our measurements but is violated once the phase change begins to occur. We find a positive correlation between networked and homopolar bond percentage with nonlinearity and a corresponding negative correlation of nonlinearity with crystalline bond percentage. The nonlinearity measurements show an enhancement in material nonlinear index by a factor of approximately 4 times at the annealing temperature of $326^{\circ} \mathrm{C}$ (from $0.5 \times 10^{-18} \mathrm{~W} / \mathrm{m}^{2}$ to $2.2 \times 10^{-18} \mathrm{~W} / \mathrm{m}^{2}$ ). This annealing temperature corresponds to the temperature of minimum crystallinity and therefore maximum homopolar and network bond percentage. This verifies that the increased number of crystalline bonds in the thermally evaporated films was reducing the nonlinear index. After annealing the films back into an amorphous phase, the nonlinearity begins to recover. The maximum value of nonlinear index of $2.2 \times 10^{-18} \mathrm{~W} / \mathrm{m}^{2}$ is still below the bulk value of $8-10 \times 10^{-18} \mathrm{~m}^{2} / \mathrm{W}$ $[16,18,24,41,42]$. Using intermediate temperatures and longer times could lead to different bond concentrations which many have higher nonlinear indices. Changing the quenching conditions may also impact the degree of crystallinity in the thin films. Annealing a chalcogenide initially reduces its long range order and eventually causes the growth of $\mathrm{GeSe}_{2}$ and $\mathrm{Se}_{2} \mathrm{Sb}_{3}$ crystals depending on the annealing temperature [33,44]. We observe a similar pattern in the initial increase in amorphousness followed by crystallization. Previous annealing studies show at higher temperatures and shorter annealing times a lower crystallinity can be obtained [33,39]. Our study implies that these conditions will result in an even higher nonlinearity. Concentrations of Ge-Ge, $\mathrm{Sb}-\mathrm{Sb}$, and $\mathrm{Se}-\mathrm{Se}$ all increased with the increased in nonlinearity. Se-Se, Ge-Ge and $\mathrm{Sb}-\mathrm{Sb}$ bonds all have been linked to higher nonlinearities in previous compositional studies as well $[16,42,47]$. This makes it difficult to ascertain the exact origin of the nonlinearity enhancement in 
the annealed films. Nonlinear index increases significantly with characteristic molecular length or delocalization (kurtosis) of the electron in the material [54]. The deposited film likely consists of a network broken up by crystallites and wrong bonds that form during evaporation. The reduction in crystallinity could correspond to the rebuilding of the chalcogen covalent network. This would increase the effective molecular length of the glassy matrix, increase the delocalization of electron states and increase the third order nonlinearity.

(a)

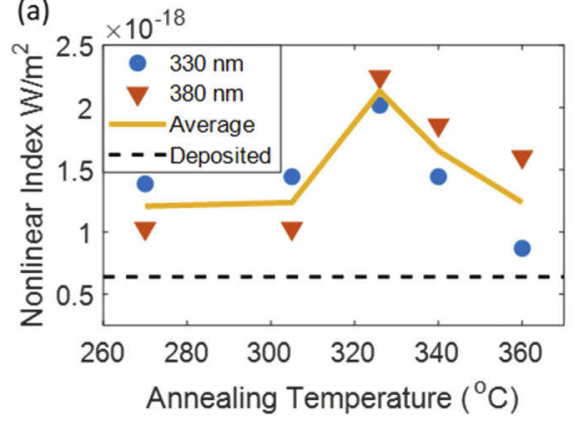

(b)

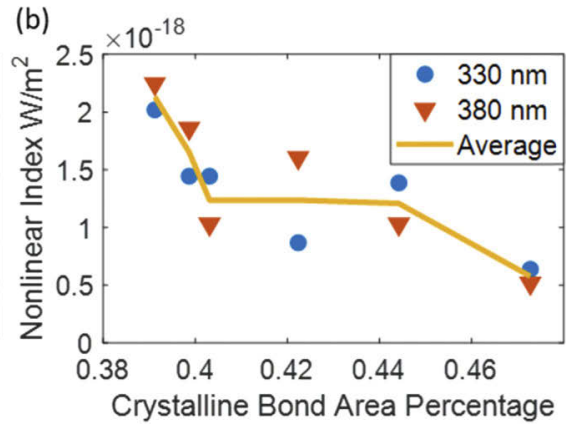

Fig. 7. (a) The measured nonlinear index of annealed chalcogenide waveguides at $1550 \mathrm{~nm}$. $330 \mathrm{~nm}$ waveguides are in blue while $380 \mathrm{~nm}$ waveguides are in red. Nonlinear index is determined by matching the supercontinuum broadening with split-step simulations over the region of $1 \mu \mathrm{m}$ to $1.7 \mu \mathrm{m}$. The nonlinear index is observed to increase with increasing annealing temperature then decrease as the phase begins to change. (b) The dependence of nonlinearity on crystalline bond percentage. We observe a negative correlation between nonlinearity and crystalline bond percentage in annealed GeSbSe waveguides. This matched by a positive correlation between homopolar bonding, networked bonding, and nonlinearity.

\section{Conclusion}

In conclusion, we have demonstrated the enhancement of nonlinearity in thermally evaporated chalcogenide through thermal annealing. This thermal treatment differs from previous studies as it does not rely on the formation of nanocrystals but instead is a method for rectifying the high concentration of crystalline bonds formed during the evaporation process [44]. This process of converting more bonds into networked and homopolar bonds increases the material nonlinearity closer to that of the bulk glass. We have also demonstrated a significant decrease in propagation loss in thermally annealed waveguides which can be used to produce higher quality waveguides and resonators for integrated nonlinear photonic circuits. Lastly, we have observed that annealing induces small changes in material dispersion which could be used to tailor the dispersion of devices. Third order nonlinear processes are highly sensitive to dispersion and annealing could be used as a post process method to optimize the dispersion of a resonator or waveguide to compensate for unavoidable variation during fabrication.

\section{Funding}

Defense Advanced Research Projects Agency (W911NF-15-1-0621); Air Force Office of Scientific Research (FA9550-15-1-0506); Office of Naval Research (N00014-19-1-2251); University of Colorado; U.S. Department of EducationP200A180012; QuEST Seed Grant Program. 


\section{Acknowledgments}

The authors gratefully acknowledge Scott Papp and Hojoong Jung of NIST-Boulder for e-beam fabrication of waveguides, Brooks Christensen for technical assistance and Cherian Joseph Mathai for ellipsometry measurements.

\section{Disclosures}

The authors declare no conflicts of interest.

\section{References}

1. M. R. Krogstad, S. Ahn, W. Park, and J. T. Gopinath, "Linear and Nonlinear Optical Properties of Ge-Sb-Se Waveguides at Telecom Wavelengths," in Conference on Lasers and Electro-Optics (2016), paper SF1P.2.

2. D.-Y. Choi, A. Wade, S. Madden, R. Wang, D. Bulla, and B. Luther-Davies, "Photo-induced and Thermal Annealing of Chalcogenide Films for Waveguide Fabrication," Phys. Procedia 48, 196-205 (2013).

3. J. W. Choi, Z. Han, B.-U. Sohn, G. F. R. Chen, C. Smith, L. C. Kimerling, K. A. Richardson, A. M. Agarwal, and D. T. H. Tan, "Nonlinear characterization of GeSbS chalcogenide glass waveguides," Sci. Rep. 6(1), 39234 (2016).

4. W. Gao, M. E. Amraoui, M. Liao, H. Kawashima, Z. Duan, D. Deng, T. Cheng, T. Suzuki, Y. Messaddeq, and Y. Ohishi, "Mid-infrared supercontinuum generation in a suspended-core $\mathrm{As}_{2} \mathrm{~S}_{3}$ chalcogenide microstructured optical fiber," Opt. Express 21(8), 9573-9583 (2013).

5. M. R. Karim, B. M. A. Rahman, and G. P. Agrawal, "Mid-infrared supercontinuum generation using dispersionengineered $\mathrm{Ge}_{11.5} \mathrm{As}_{24} \mathrm{Se}_{64.5}$ chalcogenide channel waveguide," Opt. Express 23(5), 6903-6914 (2015).

6. M. R. E. Lamont, B. Luther-Davies, D.-Y. Choi, S. Madden, and B. J. Eggleton, "Supercontinuum generation in dispersion engineered highly nonlinear $(\gamma=10 / \mathrm{W} / \mathrm{m}) \mathrm{As}_{2} \mathrm{~S}_{3}$ chalcogenide planar waveguide," Opt. Express 16(19), 14938-14944 (2008).

7. K. F. Lee, N. Granzow, M. A. Schmidt, W. Chang, L. Wang, Q. Coulombier, J. Troles, N. Leindecker, K. L. Vodopyanov, P. G. Schunemann, M. E. Fermann, P. S. J. Russell, and I. Hartl, "Midinfrared frequency combs from coherent supercontinuum in chalcogenide and optical parametric oscillation," Opt. Lett. 39(7), 2056-2059 (2014).

8. R. A. Martinez, G. Plant, K. Guo, B. Janiszewski, M. J. Freeman, R. L. Maynard, M. N. Islam, F. L. Terry, O. Alvarez, F. Chenard, R. Bedford, R. Gibson, and A. I. Ifarraguerri, "Mid-infrared supercontinuum generation from 1.6 to $11 \mu \mathrm{m}$ using concatenated step-index fluoride and chalcogenide fibers," Opt. Lett. 43(2), 296-299 (2018).

9. J-É Tremblay, M. Malinowski, K. A. Richardson, S. Fathpour, and M. C. Wu, "Picojoule-level octave-spanning supercontinuum generation in chalcogenide waveguides," Opt. Express 26(16), 21358-21363 (2018).

10. S. Xie, N. Tolstik, J. C. Travers, E. Sorokin, C. Caillaud, J. Troles, P. S. J. Russell, and I. T. Sorokina, "Coherent octave-spanning mid-infrared supercontinuum generated in $\mathrm{As}_{2} \mathrm{~S}_{3}$-silica double-nanospike waveguide pumped by femtosecond Cr:ZnS laser," Opt. Express 24(11), 12406-12413 (2016).

11. H. P. T. Nguyen, K. Nagasaka, T. H. Tuan, T. S. Saini, X. Luo, T. Suzuki, and Y. Ohishi, "Highly coherent supercontinuum in the mid-infrared region with cascaded tellurite and chalcogenide fibers," Appl. Opt. 57(21), 6153-6163 (2018).

12. C. R. Petersen, U. Møller, I. Kubat, B. Zhou, S. Dupont, J. Ramsay, T. Benson, S. Sujecki, N. Abdel-Moneim, Z Tang, D. Furniss, A. Seddon, and O. Bang, "Mid-infrared supercontinuum covering the 1.4-13.3 $\mu$ m molecular fingerprint region using ultra-high NA chalcogenide step-index fibre,” Nat. Photonics 8(11), 830-834 (2014).

13. F. Charpentier, B. Bureau, J. Troles, C. Boussard-Plédel, K. M.-L. Pierrès, F. Smektala, and J.-L. Adam, "Infrared monitoring of underground CO2 storage using chalcogenide glass fibers," Opt. Mater. 31(3), 496-500 (2009).

14. M. Hubert, "Chalcogenide Glasses for Infrared Applications: New Synthesis Routes and Rare Earth Doping," (2012).

15. C. R. Petersen, N. Prtljaga, M. Farries, J. Ward, B. Napier, G. R. Lloyd, J. Nallala, N. Stone, and O. Bang, "Mid-infrared multispectral tissue imaging using a chalcogenide fiber supercontinuum source," Opt. Lett. 43(5), 999-1002 (2018)

16. L. Petit, N. Carlie, H. Chen, S. Gaylord, J. Massera, G. Boudebs, J. Hu, A. Agarwal, L. Kimerling, and K. Richardson, "Compositional dependence of the nonlinear refractive index of new germanium-based chalcogenide glasses," J. Solid State Chem. 182(10), 2756-2761 (2009).

17. M. Olivier, J. C. Tchahame, P. Němec, M. Chauvet, V. Besse, C. Cassagne, G. Boudebs, G. Renversez, R. Boidin, E. Baudet, and V. Nazabal, "Structure, nonlinear properties, and photosensitivity of $\left(\mathrm{GeSe}_{2}\right)_{100-\mathrm{x}}\left(\mathrm{Sb}_{2} \mathrm{Se}_{3}\right)_{\mathrm{x}}$ glasses," Opt. Mater. Express 4(3), 525-540 (2014).

18. T. Wang, X. Gai, W. Wei, R. Wang, Z. Yang, X. Shen, S. Madden, and B. Luther-Davies, "Systematic z-scan measurements of the third order nonlinearity of chalcogenide glasses," Opt. Mater. Express 4(5), 1011-1022 (2014).

19. V. S. Shiryaev and M. F. Churbanov, "1 - Preparation of high-purity chalcogenide glasses," in Chalcogenide Glasses, J.-L. Adam and X. Zhang, eds. (Woodhead Publishing, 2014), pp. 3-35.

20. I. Pethes, R. Chahal, V. Nazabal, C. Prestipino, A. Trapananti, S. Michalik, and P. Jóvári, "Chemical Short-Range Order in Selenide and Telluride Glasses," J. Phys. Chem. B 120(34), 9204-9214 (2016). 
21. R. M. J. S. Sanghera L, B. Shaw, L. E. Busse, V. Q. Nguyen, P. C. Pureza, B. C. Cole, B. B. Harrison, I. D. Aggarwal, R. Mossadegh, F. Kung, D. Talley, and D. Roselle, "Development and Infrared Applications of Chalcogenide Glass Optical Fibers," Fiber Integr. Opt. 19(3), 251-274 (2000).

22. Schott Glass, "Infrared Chalcogenide Glass IRG 25," Infrared Chalcogenide Glass IRG 25. https://www.us.schott.com/d/advanced_optics/d91edc7a-ce5a-4d0a-a772-02278ec382c0/1.12/schott-infraredchalcogenide-glasses-irg-25-english-us-10042017.pdf.

23. W.-H. Wei, R.-P. Wang, X. Shen, L. Fang, and B. Luther-Davies, "Correlation between Structural and Physical Properties in Ge-Sb-Se Glasses," J. Phys. Chem. C 117(32), 16571-16576 (2013).

24. L. Chen, F. Chen, S. Dai, G. Tao, L. Yan, X. Shen, H. Ma, X. Zhang, and Y. Xu, "Third-order nonlinearity in Ge-Sb-Se glasses at mid-infrared wavelengths," Mater. Res. Bull. 70, 204-208 (2015).

25. V. Nazabal, F. Charpentier, J.-L. Adam, P. Nemec, H. Lhermite, M.-L. Brandily-Anne, J. Charrier, J.-P. Guin, and A. Moréac, "Sputtering and Pulsed Laser Deposition for Near- and Mid-Infrared Applications: A Comparative Study of $\mathrm{Ge}_{25} \mathrm{Sb}_{10} \mathrm{~S}_{65}$ and $\mathrm{Ge}_{25} \mathrm{Sb}_{10} \mathrm{Se}_{65}$ Amorphous Thin Films," Int. J. Appl. Ceram. Tech. 8(5), 990-1000 (2011).

26. E. Baudet, C. Cardinaud, A. Girard, E. Rinnert, K. Michel, B. Bureau, and V. Nazabal, "Structural analysis of RF sputtered Ge-Sb-Se thin films by Raman and X-ray photoelectron spectroscopies," J. Non-Cryst. Solids 444, 64-72 (2016).

27. J. Orava, T. Kohoutek, and T. Wagner, "9 - Deposition techniques for chalcogenide thin films," in Chalcogenide Glasses, J.-L. Adam and X. Zhang, eds. (Woodhead Publishing, 2014), pp. 265-309.

28. S. Song, N. Carlie, J. Boudies, L. Petit, K. Richardson, and C. B. Arnold, "Spin-coating of $\mathrm{Ge}_{23} \mathrm{Sb}_{7} \mathrm{~S}_{70}$ chalcogenide glass thin films," J. Non-Cryst. Solids 355(45-47), 2272-2278 (2009).

29. D. M. Mattox, Handbook of Physical Vapor Deposition (PVD) Processing. (William Andrew, 2010).

30. M. R. Krogstad, "Ge-Sb-Se Chalcogenide Glass for Near- and Mid-Infrared Nonlinear Photonics," p. 228.

31. T. Kuriakose, E. Baudet, T. Halenkovič, M. M. R. Elsawy, P. Němec, V. Nazabal, G. Renversez, and M. Chauvet, "Measurement of ultrafast optical Kerr effect of $\mathrm{Ge}-\mathrm{Sb}-\mathrm{Se}$ chalcogenide slab waveguides by the beam self-trapping technique," Opt. Commun. 403, 352-357 (2017).

32. S. Serna, H. Lin, C. Alonso-Ramos, A. Yadav, X. L. Roux, K. Richardson, E. Cassan, N. Dubreuil, J. Hu, and L. Vivien, "Nonlinear optical properties of integrated GeSbS chalcogenide waveguides," Photonics Res. 6(5), B37-B42 (2018).

33. M. M. Wakkad, E. K. Shokr, and S. H. Mohamed, "Crystallization Kinetics and Some Physical Properties of As-Prepared and Annealed Ge-Sb-Se Chalcogenide Glasses," Phys. Stat. Sol. (a) 183(2), 399-411 (2001).

34. W. Callister, Material Science and Engineering, 9th ed. (Wiley, USA, 2014).

35. L. Calvez, "Chalcogenide glasses and glass-ceramics: Transparent materials in the infrared for dual applications," C. R. Phys. 18(5-6), 314-322 (2017).

36. J. Orava and A. L. Greer, "Fast crystal growth in glass-forming liquids," J. Non-Cryst. Solids 451, 94-100 (2016).

37. J. H. Lee, J. H. Yi, W. H. Lee, B. J. Park, and Y. G. Choi, "Crystallization behavior of Ge-Sb-Se glasses in the compositional range for use as molded lenses," J. Non-Cryst. Solids 481, 21-26 (2018).

38. A. Kaswan, V. S. S. Kumari, D. K. Patidar, N. S. Saxena, and K. Sharma, "Kinetics of crystallization of Ge30-xSe70Sbx $(\mathrm{x}=15,20,25)$ chalcogenide glasses," Process Appl. Ceram. 8(1), 25-30 (2014).

39. N. Kitamura, "Two types of structural relaxations around the deformation temperature of Ge20Sb15Se65 glass," J. Non-Cryst. Solids 492, 126-129 (2018).

40. J. Orava and A. L. Greer, "Chapter 17 - Chalcogenides for Phase-Change Memory," in Handbook of Thermal Analysis and Calorimetry, vol. 6, S. Vyazovkin, N. Koga, and C. Schick, eds. (Elsevier Science B.V., 2018), pp. 685-734.

41. C. Goncalves, M. Kang, B.-U. Sohn, G. Yin, J. Hu, D. T. H. Tan, and K. Richardson, "New Candidate Multicomponent Chalcogenide Glasses for Supercontinuum Generation," Appl. Sci. 8(11), 2082 (2018).

42. S. Dai, F. Chen, Y. Xu, Z. Xu, X. Shen, T. Xu, R. Wang, and W. Ji, "Mid-infrared optical nonlinearities of chalcogenide glasses in Ge-Sb-Se ternary system," Opt. Express 23(2), 1300-1307 (2015).

43. P. Němec, M. Olivier, E. Baudet, A. Kalendová, P. Benda, and V. Nazabal, "Optical properties of (GeSe2)100-x(Sb2Se3)x glasses in near- and middle-infrared spectral regions," Mater. Res. Bull. 51, 176-179 (2014).

44. Y. Huang, F. Chen, B. Qiao, S. Dai, Q. Nie, and X. Zhang, "Improved nonlinear optical properties of chalcogenide glasses in Ge-Sn-Se ternary system by thermal treatment," Opt. Mater. Express 6(5), 1644-1652 (2016).

45. J. Tauc, "Optical properties and electronic structure of amorphous Ge and Si," Mater. Res. Bull. 3(1), 37-46 (1968).

46. H. Guo, C. Hou, F. Gao, A. Lin, P. Wang, Z. Zhou, M. Lu, W. Wei, and B. Peng, "Third-order nonlinear optical properties of GeS2-Sb2S3-CdS chalcogenide glasses," Opt. Express 18(22), 23275-23284 (2010).

47. B. Qiao, S. Dai, Y. Xu, P. Zhang, X. Shen, T. Xu, Q. Nie, W. Ji, and F. Chen, "Third-order optical nonlinearities of chalcogenide glasses within Ge-Sn-Se ternary system at a mid-infrared window," Opt. Mater. Express 5(10), 2359-2365 (2015).

48. H. Liu, Z. Liu, E. S. Lamb, and F. Wise, "Self-similar erbium-doped fiber laser with large normal dispersion," Opt. Lett. 39(4), 1019-1021 (2014).

49. B. Oktem, C. Ülgüdür, and FÖ Ilday, "Soliton-similariton fibre laser," Nat. Photonics 4(5), 307-311 (2010).

50. G. Guery, J. D. Musgraves, C. Labrugere, E. Fargin, T. Cardinal, and K. Richardson, "Evolution of glass properties during a substitution of $\mathrm{S}$ by $\mathrm{Se}$ in $\mathrm{Ge}_{28} \mathrm{Sb}_{12} \mathrm{~S}_{60-\mathrm{x}} \mathrm{Se}_{\mathrm{x}}$ glass network," J. Non-Cryst. Solids 358(15), 1740-1745 (2012). 


\section{Optics EXPRESS}

51. A. R. Motamedi, A. H. Nejadmalayeri, A. Khilo, F. X. Kärtner, and E. P. Ippen, "Ultrafast nonlinear optical studies of silicon nanowaveguides," Opt. Express 20(4), 4085-4101 (2012).

52. M. R. Karim, B. M. A. Rahman, and G. P. Agrawal, "Dispersion engineered $\mathrm{Ge}_{11.5} \mathrm{As}_{24} \mathrm{Se}_{64.5}$ nanowire for supercontinuum generation: A parametric study," Opt. Express 22(25), 31029-31040 (2014).

53. J. M. Dudley, G. Genty, and S. Coen, "Supercontinuum generation in photonic crystal fiber," Rev. Mod. Phys. 78(4), 1135-1184 (2006).

54. R. W. Boyd, Nonlinear Optics, 3rd ed. (Academic Press, Inc., 2008). 